\title{
Effect of structural differences of carbon nanotubes and graphene based iridium-NHC materials on the hydrogen transfer catalytic activity
}

\author{
Matías Blanco, ${ }^{a}$ Patricia Álvarez, ${ }^{a}$ Clara Blanco, ${ }^{a}$ M. Victoria Jiménez, ${ }^{*, b}$ Javier Fernández- \\ Tornos, ${ }^{b}$ Jesús J. Pérez-Torrente, ${ }^{b}$ Javier Blasco, ${ }^{c}$ Gloria Subías, ${ }^{c}$ Vera Cuartero, ${ }^{d}$ Luis A. Oro, ${ }^{b}$ and \\ Rosa Menéndez, $z^{* a}$
}

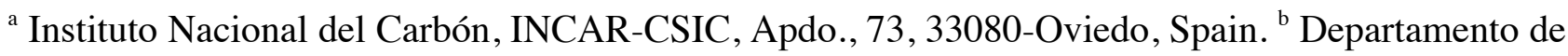
Química Inorgánica, Instituto de Síntesis Química y Catálisis Homogénea-ISQCH, Universidad de Zaragoza-CSIC, 50009-Zaragoza, Spain. ' Instituto de Ciencia de Materiales de Aragón-ICMA, Departamento de Física de la Materia Condensada, CSIC-Universidad de Zaragoza, 50009Zaragoza, Spain. ${ }^{\mathrm{d}}$ ESRF-The European Synchrotron, 71, Avenue des Martyrs, Grenoble, France

\section{ABSTRACT}

A proper design of heterogeneous molecular catalysts supported on carbon materials requires a systematic study of "metal-carbon support interactions" and their influence on catalytic activity. In this study, hybrid materials containing covalently anchored iridium N-heterocyclic carbene (NHC) organometallic complexes have been successfully prepared from oxidized and partially reduced carbon nanotubes (CNTs). The preparation method for these supported materials relies on the selective functionalization of the superficial hydroxylic groups using the imidazolium salt, 1-(3hydroxypropyl)-3-methyl-1H-imidazol-3-ium chloride. The hydrogen transfer catalysis activity of these nanotube-based hybrid catalysts was tested by the reduction of cyclohexanone to cyclohexanol with 2-propanol, and the results of the tests were compared with those obtained using similar hybrid graphene-based catalysts. While EXAFS analysis revealed a common first coordination shell of the iridium atom for all the hybrid materials examined, independently of whether they were either supported on carbon nanotubes or graphene materials, catalytic activity in all the reduced materials was significantly superior. Moreover, catalytic systems based on reduced

*CORRESPONDING AUTHORS: Tel.:+34 985543270. E-mail: rosmenen@incar.csic.es (R. Menéndez). Tel.: +34876553794. E-mail: vjimenez@unizar.es (M. V. Jiménez). 
CNTs exhibited a better performance than those based on reduced graphene materials. Both these facts suggest there is a positive correlation between hydrogen transfer catalytic activity, reconstruction of the aromatic carbon structure and the smaller amount of oxygen functional groups.

\section{Introduction}

Technological development has provided us with available new one, two and three -dimensional carbon materials with a specific spatial and geometrical structure [1,2]. These highly versatile carbon materials are being currently used not only in electronic devices $[3,4,5,6]$ but also as catalyst supports since their graphitic structure makes them inert in many chemical media [7]. For these reasons, in addition to their use as carbocatalysts, where oxidized functionalization is generally required $[8,9,10]$, they have been profusely used as supports for hybrid materials having metal oxides, nanoparticles or molecular catalysts as the active sites $[7,11,12,13,14]$. These supports were initially evaluated as "innocent" materials due to their uniform hybridization, ordered structure and chemical inertness but it is known that the metal-support interactions are strongly dependent not only on the nature of the metal, but also on the type of carbon material chosen because their electronic [15,16], thermal [17] or mechanical properties [18,19] depend on their preparation method, origin and further modifications involving different surface treatments [20,21].

Carbon nanotubes (CNT) [22] and graphene [2] are the mono- and bi-dimensional long-range ordered versions, respectively, of these carbon materials. The synthetic methods used for carbon oxygen functionalization are well-established procedures. Graphene oxide (GO) is obtained from a severe oxidation process commonly employed for the chemical synthesis of graphene from graphite $[23,24]$. The $\mathrm{sp}^{2}$ lattice of the graphene is disrupted upon oxidation by the introduction of oxygen functional groups, predominantly $\mathrm{OH}$ and epoxy in the interior of the basal plane while carboxylic acids are formed at the edges, and also where there are morphological defects (carbon atom vacancies) [25]. On the other hand, the oxidation processes, what introduce oxygen functionalization in the nanotubes (namely CNTO), are currently used as a purification step after synthesis [26]. Both oxidized carbon nanomaterials, GO and CNTO, have been utilized previously as catalysts themselves or as catalyst supports by making use of the surface groups in order to immobilize the active species [27,28,29,30]. Thus, not only metallic nanoparticles, but also enzymes or organometallic complexes have been anchored to these oxidized carbon nanomaterials 
using esterification/amidation reactions with oxygen groups. The activation of carboxylic acids with $\mathrm{SOCl}_{2}$ [31] or carbodiimides [32], and the reactivity of hydroxylic groups towards silanes [33] are routinely employed in order to functionalize CNTO and GO with the catalyst precursors. In general, the catalytic studies conducted on nanohybrid catalyst based on CNT or graphene systems have shown promising results in terms of activity, selectivity, stability and/or cyclability compared to the homogeneous or heterogeneous traditional systems [34].

Recently, our group found a protocol to immobilize iridium N-heterocyclic carbene (NHC) complexes on GO and thermally reduced GO materials by taking advantage of the carbon-based organic chemistry of the surface hydroxylic groups instead of using traditional siloxane chemistry [35]. The hybrid graphene-iridium-NHC materials were found to be efficient hydrogen-transfer catalysts exhibiting good recyclability. The effectiveness of the $\operatorname{Ir}(\mathrm{I})-\mathrm{NHC}$ complexes as homogeneous catalysts in transfer hydrogenation of unsaturated compounds $[36,37,38,39,40,41]$, in particular, those with hemilabile $\mathrm{O}$ - and $\mathrm{N}$ - donor functions in the NHC carbene ligand [42,43], is well known in the literature. In addition, an increase in the transfer hydrogenation catalytic activity of Ir-NHC complexes based on hemilabile O- and N- donor functions supported on CNT has been observed. [44] However, to date no systematic comparison of the catalytic activities and selectivities of different carbon-material based catalytic systems has been carried out and, to the best of our knowledge, the present study is unique in trying to establish the possible influence of the structure, surface chemistry and the reconstruction of the aromatic network on the catalytic activity of a hybrid organometallic complex-CNTO/GO carbon nanomaterial system. Despite the similar structure and properties of both materials, the geometrical and spatial differences could give rise to different local environments thereby influencing the catalytic activity.

This work has to tackle two critical points. Firstly, the covalent functionalization of oxidized and thermally reduced carbon nanotubes through surface -OH groups to produce iridium-supported NHC-CNTO complexes comparable to hybrid iridium NHC-GO catalysts has to be performed. Secondly, study the catalytic activity in the transfer hydrogenation of cyclohexanone with 2propanol to compare with that of hybrid GO catalysts materials. Specific features of the structure and the surface chemistry of the hybrid catalysts have been used in this work to explain the differences in the catalytic performance. 


\section{Experimental}

\subsection{Materials}

All the chemicals, including the graphite powder and multiwalled carbon nanotubes, were purchased from Aldrich. Reagent or HPLC grade was employed in all the experiments. Solvents were distilled immediately prior to use with appropriate drying agents or obtained from a Solvent Purification System (Innovative Technologies).

The oxidized CNTs (CNTO) utilized in this work were prepared by acid treatment of commercial bundle-type CNTs, as described previously [45]. The GO utilized in this work was prepared by applying a modified Hummers method to the commercial graphite, as reported in detail elsewhere [46]. TRGO and TRCNTO were obtained from GO and CNTO respectively by thermal treatment at $400^{\circ} \mathrm{C}$ in a horizontal furnace, under a nitrogen flow of $50 \mathrm{~cm}^{3} \mathrm{~min}^{-1}$. The residence time at the final temperature was $60 \mathrm{~min}[46]$.

The imidazolium salt $\left[\mathrm{MeImH}\left(\mathrm{CH}_{2}\right)_{3} \mathrm{OH}\right] \mathrm{Cl}(\mathbf{1})$ [47] and the compound $[\mathrm{Ir}(\mu-\mathrm{OMe})(\mathrm{cod})]_{2}[48]$ were prepared according to standard literature procedures.

\subsection{Characterization of Nanotube and Graphene Materials and Hybrid Catalysts}

Nuclear magnetic resonance (NMR) spectra were recorded on a Bruker Advance 400 spectrometer operating at $400.16 \mathrm{MHz}\left({ }^{1} \mathrm{H}\right)$. NMR chemical shifts are reported in ppm relative to tetramethylsilane and referenced to partially deuterated solvent resonances. Transmission electron microscopy (TEM) spectra were obtained on a JEOL 2000 EX-II instrument operating at $160 \mathrm{kV}$. Images of high-resolution transmission electron microscopy (HRTEM) were recorded using a JEOL JEM-2100F transmission electron microscope, equipped with a field-emission-gun (FEG) operating at $200 \mathrm{kV}$, and fitted with an Oxford Instruments microprobe to perform Energy-dispersive X-ray spectroscopy $(\mathrm{EDX})$, in order to verify the atomic composition of the catalyst. The samples were prepared by casting a few drops of $1 \mathrm{mg} \mathrm{mL}^{-1}$ ethanol suspensions of the materials over the carbon grids. To minimize exposure of the samples to the air, the suspensions were transferred to a lacey carbon grid using a glovebox filled with ultrahigh-purity argon and then to the TEM holder in order to minimize the time required to introduce them into the microscope. Elemental analyses were performed on a LECO-CHNS-932 micro-analyser equipped with a LECO-VTF-900 furnace coupled to a micro-analyzer. The X-ray photoemission spectroscopy (XPS) spectra were recorded 
using a SPECS system operating under a pressure of $10^{-7} \mathrm{~Pa}$ and equipped with a $\mathrm{Mg} \mathrm{K} \alpha \mathrm{X}$-ray source. The functional groups in the graphene materials were quantified by deconvolution of the high resolution C1s XPS peak employing Gaussian and Lorentzian functions [49]. The binding energy profiles were deconvoluted as follows: undamaged structures of $\mathrm{sp}^{2}$-hybridized carbon $\left(284.5 \mathrm{eV}\right.$ ), damaged structures or $\mathrm{sp}^{3}$-hybridized carbons (and C-N groups, $285.5 \mathrm{eV}$ ), C-O (and C$\mathrm{N}$ groups, $286.5 \mathrm{eV}), \mathrm{C}=\mathrm{O}$ functional groups $(287.7 \mathrm{eV})$ and $\mathrm{COO}$ groups at $288.7 \mathrm{eV}$. The amount of iridium present in the samples was determined by means of Inductively Coupled Plasma Mass Spectrometry (ICP-MS) in an Agilent 7700x instrument. The samples were digested following a method described elsewhere [50]. Briefly, $30 \mathrm{mg}$ of sample was treated with $5 \mathrm{~mL}$ of a mixture of concentrated nitric and hydrochloric acid (3:1 ratio) at $180{ }^{\circ} \mathrm{C}$ for $3 \mathrm{~h}$ under microwave irradiation.

X-ray absorption spectroscopy (XAS) measurements were recorded at the BL22-Claess beamline from ALBA synchrotron (Spain) and at the BM23 beamline from the European Synchrotron Radiation Facility (ESRF, France). The measurements were carried out in transmission mode on pellets with an optimized thickness at room temperature. The beam was monochromatized by a fixed-exit-offset Si (311) double crystal in ALBA and a Si (111) one in ESRF. A harmonic rejection better than $10^{-5}$ was achieved by using a Si mirror coating on a dual toroid focusing mirror installed after the monochromator in both cases. The energy resolution $\Delta \mathrm{E} / \mathrm{E}$ was estimated to be about $8 \times$

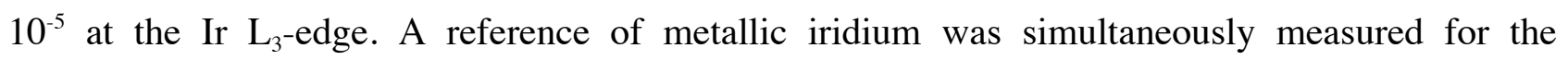
calibration of the energy. XAS spectra of metal $\mathrm{Ir}$, the complex $\left[\mathrm{IrCl}(\mathrm{cod})\left(\mathrm{MeImH}\left(\mathrm{CH}_{2}\right)_{3} \mathrm{OH}\right)\right]$ and the salt $\mathrm{IrCl}_{3}$ were also recorded as references for $\operatorname{Ir}(0), \operatorname{Ir}(\mathrm{I})$ and $\operatorname{Ir}(\mathrm{III})$ respectively. The measurements obtained from both synchrotrons are comparable. Extended X-ray absorption fine structure (EXAFS) spectra were extracted using Athena software (part of the Demeter package) [51] The Fourier transforms (FTs) of the EXAFS signals were calculated over a k-range of 3.0-13.3 $\AA^{-1}$ using a sine window. The EXAFS structural analysis was performed using theoretical phases and amplitudes calculated by means of the FEFF-6 code [52] and fits to the experimental data were carried out in R-space with the help of ARTEMIS program (also part of Demeter package) [51].

\subsection{Functionalization of Nanotube Materials with 1-(3-hydroxypropyl)-3-methyl-1H-imidazol-3-} ium chloride (1)

Using a similar procedure to that recently reported for graphene materials [35], CNTO and TRCNTO were functionalized with the imidazolium salt, 1-(3-hydroxypropyl)-3-methyl-1H- 
imidazol-3-ium chloride, $\left[\mathrm{MeImH}\left(\mathrm{CH}_{2}\right)_{3} \mathrm{OH}\right] \mathrm{Cl}$ (1), following a two-step procedure. Briefly, CNTO or TRCNTO (100 mg) was dispersed in $20 \mathrm{~mL}$ of dichloromethane (DCM). The resulting dispersion was cooled to $0{ }^{\circ} \mathrm{C}$ in an ice bath and then, $p$-nitrophenylchloroformate $(3.0 \mathrm{~g}, 15 \mathrm{mmol})$ and triethylamine $(2.1 \mathrm{~mL}, 15 \mathrm{mmol})$ were added under an inert atmosphere. The mixture was stirred for $24 \mathrm{~h}$ and allowed to reach room temperature slowly. The resulting solids were filtered and washed three times with DCM $(20 \mathrm{~mL})$ and then dried under vacuum for $2 \mathrm{~h}$. In a second step, the imidazolium salt $1(100 \mathrm{mg}, 0.560 \mathrm{mmol})$ and a catalytic amount of triethylamine $(0.2 \mathrm{~mL})$ were added, under an inert atmosphere, to the dispersions of nanotube solids obtained in step 1 in tetrahydrofuran (THF) $(15 \mathrm{~mL})$, and refluxed for $24 \mathrm{~h}$. The products were obtained by centrifugation/filtration, washed with THF (3 x $20 \mathrm{~mL})$, DCM (3 x $20 \mathrm{~mL})$, and ethanol (3 x $20 \mathrm{~mL})$ and then, vacuum dried at $100{ }^{\circ} \mathrm{C}$ in a preheated furnace until constant weight. The nanotube samples obtained were labeled as CNTO-1 and TRCNTO-1 depending on the parent material used in each case, CNT or TRCNTO, respectively.

\subsection{Preparation of Hybrid Catalysts CNTO-1-Ir and TRCNTO-1-Ir}

CNTO-1 or TRCNTO-1 (100 mg) were made to react with $[\operatorname{Ir}(\mu-\mathrm{OMe})(\mathrm{cod})]_{2}(100 \mathrm{mg}, 0.150$ $\mathrm{mmol})(\mathrm{cod}=1,5$-cyclooctadiene $)$ in THF $(10 \mathrm{~mL})$ under an argon atmosphere. The mixtures were refluxed for 2 days and then immersed in an ultrasonic bath for $30 \mathrm{~min}$ at room temperature. The resultant solids were recovered by centrifugation, washed with THF (5 x $10 \mathrm{~mL})$ and diethyl ether ( 2 x $5 \mathrm{~mL}$ ), and dried under vacuum to produce CNTO-1-Ir and TRCNTO-1-Ir.

\subsection{General Procedure for Transfer Hydrogenation Catalysis.}

The catalytic transfer hydrogenation reactions were carried out under an argon atmosphere in thick glass reaction tubes fitted with a greaseless high-vacuum stopcock. In a typical experiment, the reactor was charged with a solution of cyclohexanone $(0.52 \mathrm{~mL}, 5.0 \mathrm{mmol})$ in 2-propanol $(4.5$ $\mathrm{mL}$ ), internal standard (mesitylene, $70 \mu \mathrm{L}, 0.5 \mathrm{mmol}$ ), base $(0.1 \mathrm{~mL}, 0.025 \mathrm{mmol}$ of a $\mathrm{KOH}$ solution $0.24 \mathrm{M}$ in 2-propanol) and catalyst (0.005 mmol, $0.1 \mathrm{~mol} \%)$. The weight of the supported catalysts used in each experiment was calculated according to ICP measurements, assuming that all the iridium in the sample corresponded to active catalyst sites, $9.34 \mathrm{mg}$ of GO-1-Ir (10.2\%wt. of iridium) and $20.44 \mathrm{mg}$ of TRGO-1-Ir (4.7\%wt of iridium) were used for the GOs, and $7.7 \mathrm{mg}$ of CNTO-1-Ir (12.5\%wt. of iridium) and $9.5 \mathrm{mg}$ of TRCNTO-1-Ir (10.1\%wt. of iridium) were 
employed for the CNTs. The resulting mixture was stirred at room temperature until complete dissolution of the homogeneous catalyst, $\left[\mathrm{IrCl}(\mathrm{cod})\left(\mathrm{MeIm}\left(\mathrm{CH}_{2}\right)_{3} \mathrm{OCOCH}_{3}\right]\right.$ (Ir-ImidO) [35], or for $10 \mathrm{~min}$ in the case of the heterogeneous catalyst, and then placed in a thermostatic oil bath at the required temperature, typically $80{ }^{\circ} \mathrm{C}$. Conversions were determined by gas chromatography analysis (HP-INNOWax capillary column -0.4 $\mu \mathrm{m}, 25 \mathrm{~m}$ x $0.2 \mathrm{~mm}$ i.d.-) under the following conditions: a column temperature of $35^{\circ} \mathrm{C}(2 \mathrm{~min})$ up to $220{ }^{\circ} \mathrm{C}$ at $10{ }^{\circ} \mathrm{C} \min ^{-1}$ and a flow rate of 1 $\mathrm{cm}^{3} \min ^{-1}$ using ultrapure He as carrier gas.

Once the reaction was completed, the hybrid catalysts were recovered by centrifugation and washed with additional amounts of 2-propanol $(3 \times 10 \mathrm{~mL})$. Several catalytic cycles were performed with these materials, under the same experimental conditions, without adding any fresh catalyst precursor. The last cycle was carried out without an inert atmosphere.

\section{Results and discussion}

\subsection{Preparation and catalytic activity of Nanotube-based Hybrid Catalysts}

The nanotube-based hybrid catalysts were prepared following the reaction path depicted in Fig. 1 [35]. The "isolated" hydroxyl groups in the nanotubes react with $p$-nitrophenylchloroformate, with the subsequent formation of the corresponding $p$-nitrophenyl carbonate esters $[53,54]$. Thereafter, the nucleophilic OH-ending group of the imidazolium salt $\left[\mathrm{MeImH}\left(\mathrm{CH}_{2}\right)_{3} \mathrm{OH}\right] \mathrm{Cl}$ (1) easily displaces the $p$-nitrophenol group, resulting in the formation of the carbonate intermediates, CNTO1 and TRCNTO-1. Reaction of the imidazolium groups of these materials with the methoxo iridium $(\mathrm{I})$ dimer compound $[\operatorname{Ir}(\mu-\mathrm{OMe})(\operatorname{cod})]_{2}(\operatorname{cod}=1,5$-cyclooctadiene $)$ gave the nanotube-based hybrid materials CNTO-1-Ir and TRCNTO-1-Ir. 


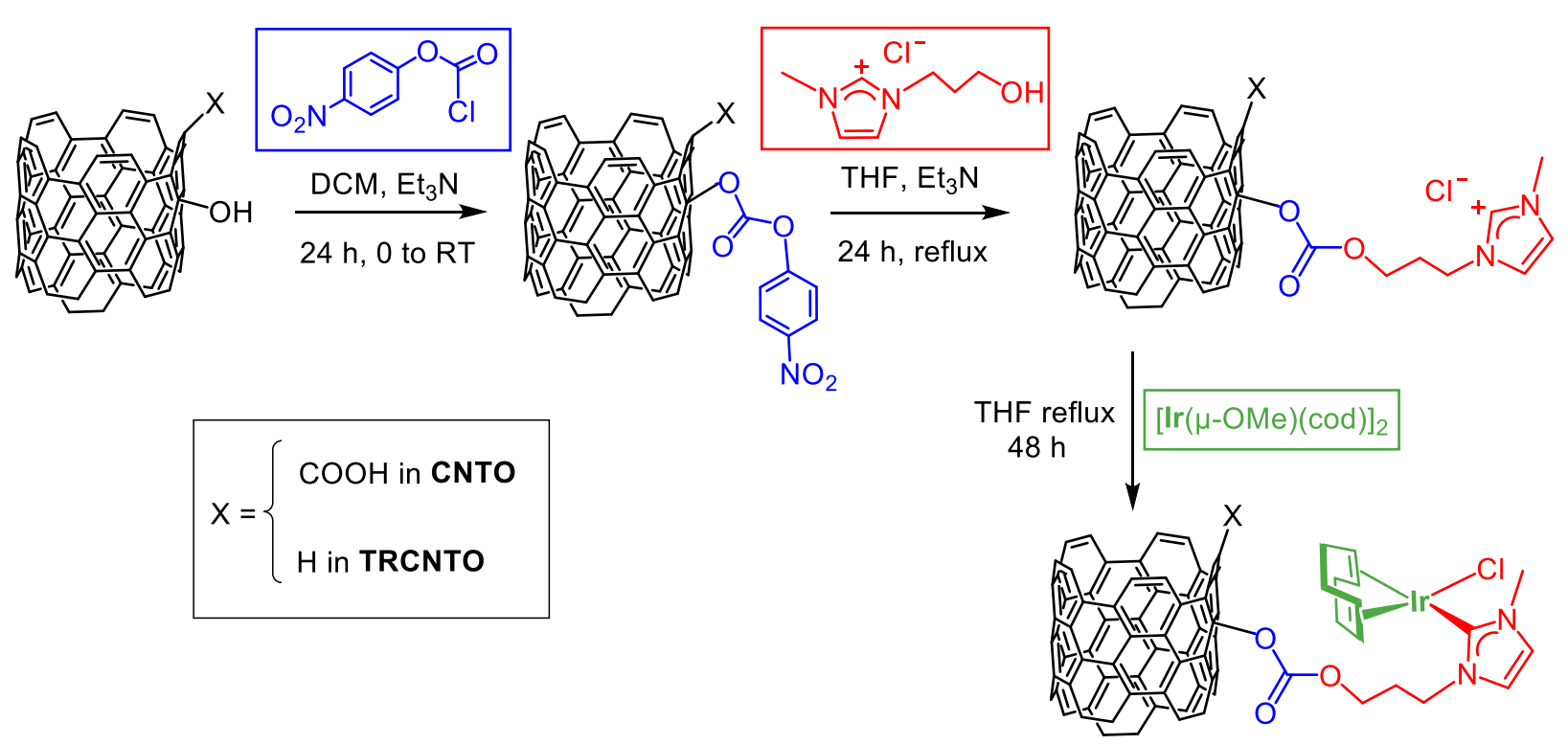

Fig. 1 - Synthesis of hybrid nanotube-based-Ir-NHC materials CNTO-1-Ir and TRCNTO-1-Ir through the covalent functionalization of the parent nanotube materials, CNTO and TRCNTO, with the imidazolium salt $\left[\mathrm{MeImH}\left(\mathrm{CH}_{2}\right)_{3} \mathrm{OH}\right] \mathrm{Cl}(\mathbf{1})$.

The covalent linkage of the imidazolium ligand to the nanotube was confirmed by the characterization of the intermediate species CNTO-1 and TRCNTO-1. These materials still form stable suspensions in acetone (see Supporting Information) and their ${ }^{1} \mathrm{H}$ NMR (acetone- $\mathrm{d}_{6}$ ) spectra show a set of signals typical of imidazolium groups, i.e., 7.41/7.35 ppm (H4 and H5) and 8.64 ppm (H2) (see Supporting Information). Neither the signals corresponding to the nitrophenyl fragment nor those corresponding to the imidazolic -OH group can be observed in the spectra. The presence of nitrogen and chlorine in their XPS spectra at a $\mathrm{N}: \mathrm{Cl}$ ratio of 2 also confirms these results (Table 1). From these analyses it is estimated that almost four times more imidazolium ligand is introduced in CNTO-1 than in TRCNTO-1, what could be justified considering a larger amount of OH groups (at basal planes) in the CNTO parent material compared to those of TRCNTO as confirmed by FTIR analysis, together a better dispersion capacity of the material in the polar reaction medium (see Supporting Information). Additionally, the larger percentage of the C-O band on the C1s XPS curve, Table 1, observed for TRCNTO is attributed to an increase in unreactive epoxy or ether groups [55]. Similar tendencies were observed in the functionalization of graphene oxides and thermally reduced graphene oxides under the same experimental conditions [35]. 


\begin{tabular}{|c|c|c|c|c|c|c|c|c|c|}
\hline \multirow[t]{2}{*}{ Sample } & \multicolumn{2}{|c|}{$\begin{array}{c}\text { Elemental } \\
\text { Analysis }\end{array}$} & \multirow[b]{2}{*}{$N$} & \multirow[b]{2}{*}{$\mathrm{Cl}$} & \multicolumn{5}{|c|}{ XPS (atom \%) } \\
\hline & $\mathrm{C} / \mathrm{O}$ & $N(w t . \%)$ & & & $C s p^{2}$ & $C s p^{3}$ & $C-O$ & $C=O$ & $\mathrm{COO}$ \\
\hline CNTO & 3.8 & 0.0 & 0.0 & 0.0 & 64.4 & 17.1 & 7.0 & 3.2 & 8.2 \\
\hline TRCNTO & 11.8 & 0.0 & 0.0 & 0.0 & 70.6 & 13.9 & 9.3 & 2.3 & 3.9 \\
\hline GO & 1.0 & 0.1 & 0.0 & 0.0 & 36.2 & 8.4 & 29.6 & 17.8 & 7.9 \\
\hline TRGO & 2.9 & 0.0 & 0.0 & 0.0 & 71.4 & 9.9 & 11.5 & 4.8 & 2.4 \\
\hline CNTO-1 & 1.7 & 5.6 & 4.7 & 2.0 & 53.7 & $20.9^{*}$ & $18.8^{*}$ & 4.7 & 1.8 \\
\hline TRCNTO-1 & 6.7 & 2.5 & 1.4 & 0.6 & 57.1 & $17.8 *$ & $16.4^{*}$ & 7.2 & 2.0 \\
\hline GO-1 & 1.4 & 6.9 & 5.6 & 2.5 & 42.7 & $24.0 *$ & $21.1 *$ & 6.2 & 6.0 \\
\hline TRGO-1 & 3.8 & 1.4 & 1.4 & 0.6 & 58.2 & $15.6^{*}$ & $14.4^{*}$ & 6.1 & 6.9 \\
\hline
\end{tabular}

* Includes the $\mathrm{C}-\mathrm{N}$ bonds

The HRTEM images in Figure 2 of the hybrid materials with the N-heterocyclic carbene (NHC) iridium complexes show homogeneous distribution of electron-dense regions associated with the supported iridium species. In spite of the presence of these anchored iridium species in CNTO and TRCNTO, they exhibit the same appearance in terms of number of layers and interlayer distances as their parents (see Supporting Information) which indicates that functionalization has not caused any damage to the nanotube layers. The iridium spots observed (also confirmed by EDX, see Supporting Information) exhibit diameters from 0.17-0.27 nm (highlighted with white circles), which are in the range of the molecular complexes, to 1.2-1.4 nm and even larger, which are the case of clusters or nanoparticles possibly formed during beam irradiation inside the microscope chamber. Similar size distributions were observed for the graphene-based hybrid catalyst [35] or even for other supported molecular iridium catalysts $[56,44]$. 


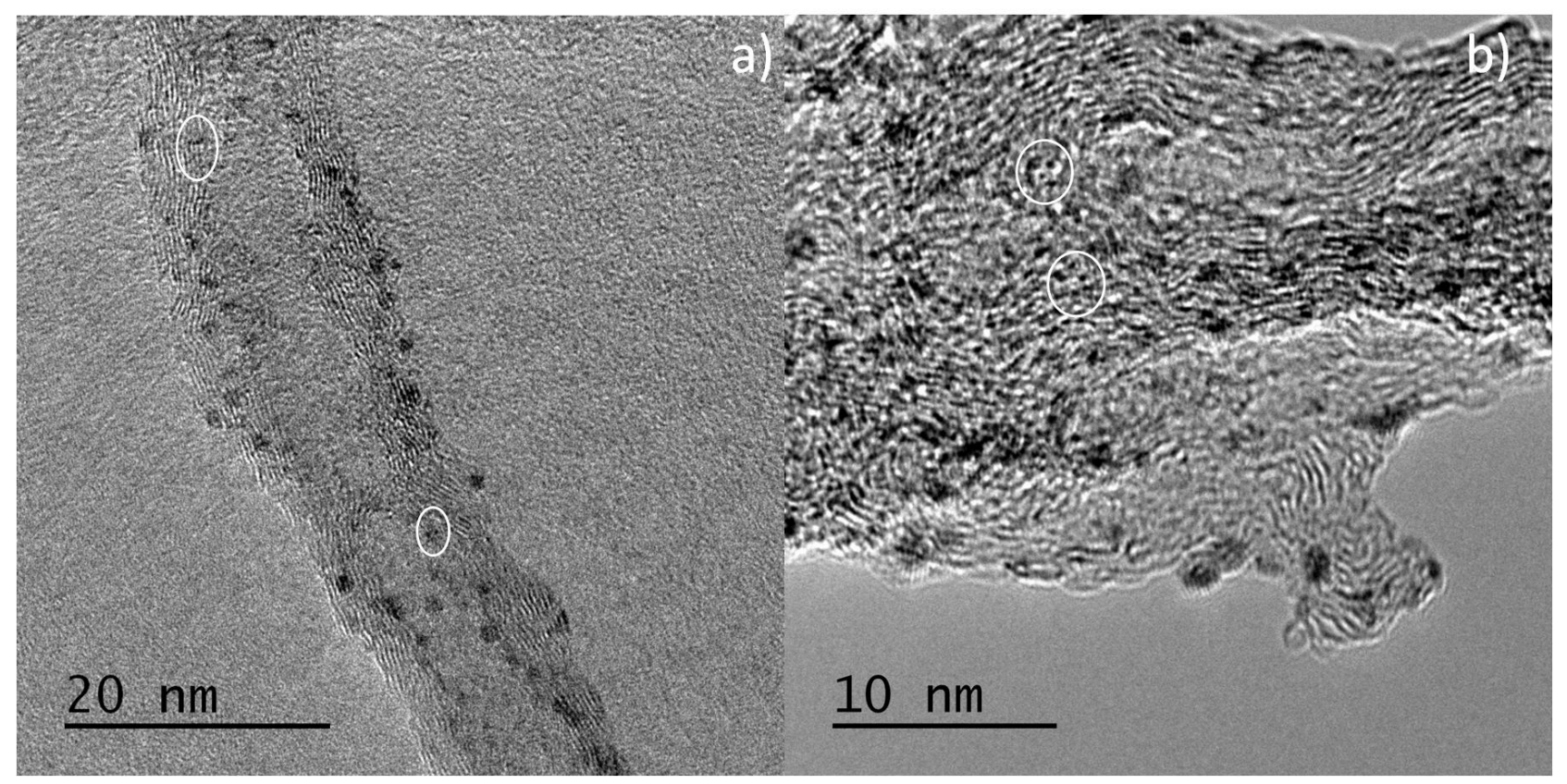

Fig. 2 - HRTEM images of a) CNTO-1-Ir and b) TRCNTO-1-Ir.

The amount of iridium in the samples, calculated by means of ICP-MS, was 12.5 and 10.1 wt.\% for CNTO-1-Ir and TRCNTO-1-Ir, respectively. The percentage of iridium in the TRCNTO-1-Ir material lies within the expected range, as is confirmed by the amount of imidazolium salt linked to the material (98\%). However, the metal content in CNTO-1-Ir is below the estimated value (52\%), which might be explained by the reduced amount of imidazolium ligands available due to steric hindrance resulting from the high density of functional groups [32].

The hydrogen-transfer catalytic activity of the samples was studied in the reduction of cyclohexanone to cyclohexanol using 2-propanol both as hydrogen source and as a non-toxic solvent. The catalytic conditions used were catalyst loads of $0.1 \mathrm{~mol} \%$, with $0.5 \mathrm{~mol} \%$ of $\mathrm{KOH}$ as co-catalyst and $80{ }^{\circ} \mathrm{C}$, i.e., identical conditions to those recently reported for the same catalyst supported on graphene materials [35]. For comparative purposes, these results are also depicted in Fig. 3 and summarized in Table 2, together with those of the molecular acetoxy-functionalized NHC complex $\left[\mathrm{IrCl}(\mathrm{cod})\left(\mathrm{MeIm}\left(\mathrm{CH}_{2}\right)_{3} \mathrm{OCOCH}_{3}\right)\right]$ (Ir-ImidO) [44]. It is worth noting that none of the iridium free nanotube and graphene materials showed any catalytic activity (see Supporting Information). Additionally, the nanotube and graphene based catalysts prepared by means of the same procedure but without NHC linkages showed no catalytic activity at all after the first cycle probably due to leaching of the iridium after washing (see Supporting Information). 


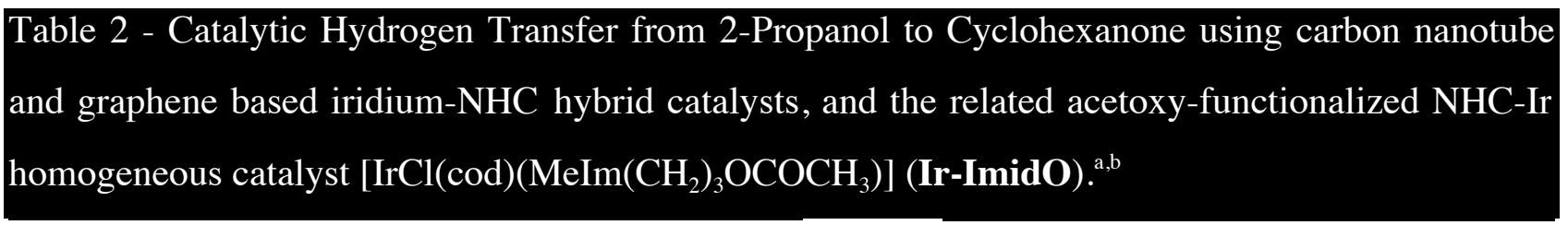

\begin{tabular}{|c|c|c|c|c|c|c|}
\hline \multirow[b]{2}{*}{ Catalyst } & \multirow[b]{2}{*}{$\begin{array}{l}\text { Time } \\
(\mathbf{m i n})\end{array}$} & \multirow[b]{2}{*}{$\begin{array}{c}\text { Conversion } \\
(\%)\end{array}$} & \multirow[b]{2}{*}{$\begin{array}{r}\mathbf{T O F}_{0} \\
\left(\mathbf{h}^{-1}\right)^{\mathrm{c}}\end{array}$} & \multirow[b]{2}{*}{$\begin{array}{r}\mathbf{T O F}_{50} \\
\left(\mathbf{h}^{-1}\right)^{\mathbf{d}}\end{array}$} & \multicolumn{2}{|c|}{ Recyclability } \\
\hline & & & & & $\begin{array}{l}\text { Mean Conversion } \\
4 \text { cycles-Argon }(\%)\end{array}$ & $\begin{array}{l}\text { Conversion } 5^{\text {th }} \\
\text { cycle on Air }(\%)\end{array}$ \\
\hline CNTO-1-Ir & 210 & 89 & 3000 & 1304 & 93 & 92 \\
\hline TRCNTO-1-Ir & 100 & 92 & 6000 & 3000 & 93 & 93 \\
\hline GO-1-Ir & 840 & 93 & 1020 & 375 & 92 & 94 \\
\hline TRGO-1-Ir & 150 & 90 & 3600 & 1685 & 93 & 92 \\
\hline Ir-ImidO & 220 & 92 & 3000 & 1485 & - & - \\
\hline
\end{tabular}

${ }^{a}$ Reaction conditions: catalyst/substrate/KOH ratio of $1 / 1000 / 5,0.1 \mathrm{~mol} \%$ of catalyst in 2 -propanol $(5 \mathrm{~mL})$ at $80{ }^{\circ} \mathrm{C}$. ${ }^{\mathrm{b}}$ The reactions were monitored by GC using mesitylene as internal standard. ${ }^{\mathrm{c}, \mathrm{d}} \mathrm{TOF}$, turnover frequency [(mol product/mol catalyst)/time (h)], were calculated at initial time $(60 \mathrm{~s})$ or at $50 \%$ of conversion, $\mathrm{TOF}_{0}, \mathrm{and}_{\mathrm{TOF}} \mathrm{T}_{50}$, respectively. 

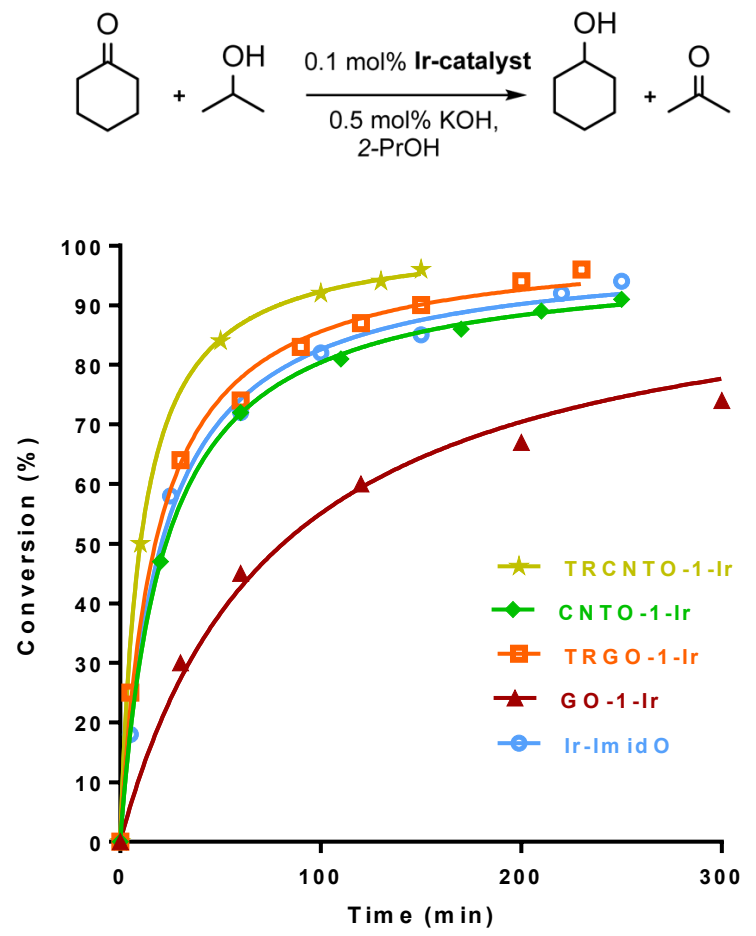

Fig. 3 - Reaction profiles showing the transfer hydrogenation of cyclohexanone by carbon nanotube and graphene based iridium-NHC hybrid catalysts and the related homogeneous molecular catalyst $\left[\operatorname{IrCl}(\mathrm{cod})\left(\mathrm{MeIm}\left(\mathrm{CH}_{2}\right)_{3} \mathrm{OCOCH}_{3}\right)\right](\mathbf{I r}-\mathbf{I m i d O})$.

Taking into account the carbon nanotube-iridium-NHC catalysts, the catalytic activity of the partially reduced materials TRCNTO-1-Ir is higher than that of CNTO-1-Ir, leading to yields higher than $90 \%$ in $100 \mathrm{~min}$ instead of $210 \mathrm{~min}$ required for the fully oxidized catalyst (conversions determined by GC with mesitylene as internal standard). A similar trend was observed for the graphene-based hybrid catalysts, which confirms that for this type of catalytic reactions, a partial reduction of the nano-support has a positive effect on the catalytic activity. Additionally, all iridium-NHC carbon nano-supports can easily recycled by a method consisting on simple centrifugation, washing of the catalysts with fresh 2-propanol $(4 \times 5 \mathrm{~mL})$ and addition of more cyclohexanone, $\mathrm{KOH}$ and 2-propanol. The recycling processes render conversions above $90 \%$ after five catalytic runs with reaction times of $2.5 \mathrm{~h}$ for TRGO-1-Ir and $13 \mathrm{~h}$ for GO-1-Ir for each run, while the catalytic reactions take $1.5 \mathrm{~h}$ and $4 \mathrm{~h}$ for TRCNTO-1-Ir and CNTO-1-Ir, respectively. All the reaction profiles are similar in the successive experiments, even in the case of the last cycle, where there is no protective atmosphere (see Supporting Information). In addition, ICP-MS 
measurements of the reused materials after the fifth catalytic runs showed similar iridium content (12.3 and 10.0 wt.\% for CNTO-1-Ir and TRCNTO-1-Ir, respectively) than that of the fresh catalysts (12.5 and 10.1 wt.\%, respectively) which reveal no leaching of the iridium on those materials.

Of special interest, however, is the fact that the catalytic activity of all the carbon nanotube-based hybrid catalysts is greater than that of their corresponding graphene material. In this regard it is worth noting that the catalytic activity of GO-1-Ir is also lower than that of the homogeneous catalyst. In order to explain these findings, a detailed characterization of the supported catalyst was performed.

\subsection{Structural features of the nanotubes and graphene-NHC-Iridium hybrid catalysts}

In order to gain an insight into the local structure of the iridium atoms in the hybrid catalysts, XAS measurements were performed at room temperature. All the XANES spectra show similar features (see Supporting Information) and their edge position is equal to that observed in $\operatorname{the} \operatorname{Ir}(\mathrm{I})$ reference compound, $\left[\mathrm{IrCl}(\mathrm{cod})\left(\mathrm{MeIm}\left(\mathrm{CH}_{2}\right)_{3} \mathrm{OH}\right)\right]$, and therefore intermediate between the metal $\mathrm{Ir}$ and $\mathrm{IrCl}_{3}$ indicating a similar state of oxidation of (I) for the Ir atoms in these hybrid catalysts (see Supporting Information). This is in agreement with the high-resolution Ir4f XPS band obtained for all hybrid nanotube and graphene based iridium catalysts (Fig. 4) which shows two peaks (corresponding to $\operatorname{Ir} 4 \mathrm{f}_{7 / 2}$ and $\operatorname{Ir} 4 \mathrm{f}_{5 / 2}$ ) centered at 62.4 and $65.6 \mathrm{eV}$, that are characteristic of iridium(I) compounds [57].

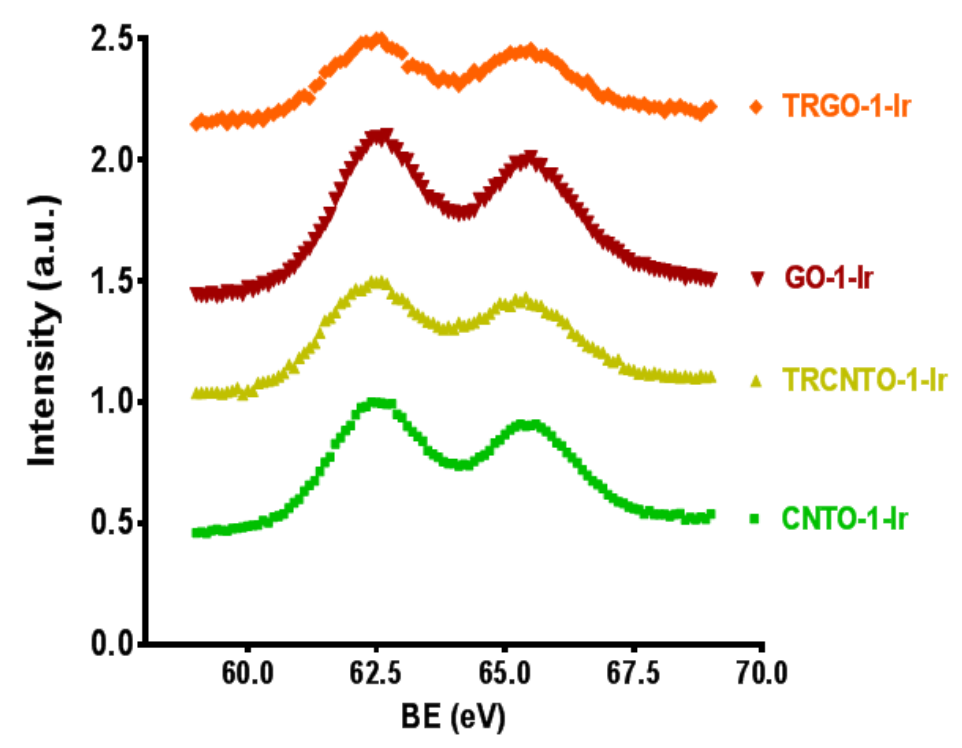


Fig. 4 - High-resolution Ir4f XPS spectra obtained for the all the hybrid carbon nanotube and graphene based iridium-NHC catalysts.

Fig. 5a presents the $\mathrm{k}^{2}$-weighted EXAFS signals for all studied hybrid catalysts and the reference compound $\left[\mathrm{IrCl}(\mathrm{cod})\left(\mathrm{MeIm}\left(\mathrm{CH}_{2}\right)_{3} \mathrm{OH}\right)\right]$ for the sake of comparison. The four hybrid catalysts show similar oscillations in the spectra though a higher damping is observed in the signal of GO-1-Ir. However, the signal for the reference compound shows a clear interference at $\mathrm{k} \sim 8-11 \AA^{-1}$. In order to highlight the differences between the compounds under study, Fig. $5 b$ displays the modulus of the FTs of the previous EXAFS spectra to provide a measure of the pseudo radial distribution function around the Ir atom. The hybrid catalysts show a first coordination shell composed by a single peak at $\mathrm{R} \sim 1.7 \AA$ (without phase shift correction) while a second peak or shoulder is observed in the reference complex close to $2.1 \AA$ (related to the above mentioned interference) that it is ascribed to the $\mathrm{Ir}-\mathrm{Cl}$ bond. Then, the first main isolated peak in the FTs of the catalysts corresponds to the first-neighbors coordination shell, which is only composed of light elements, likely ascribed to $\mathrm{C}$ (and/or some $\mathrm{O}$ ). The intensity of this peak is significantly smaller for the GO1-Ir samples than in the other three compounds. The decrease in intensity is related to the high damping observed in its EXAFS signal and indicates greater structural disorder. Structures beyond $2.2 \AA$ correspond to mixed contributions from the next-neighbors coordination shells. Although all the samples exhibit different patterns in this range, the signals are significantly weaker and broader, which prevent them from being analyzed. Therefore, EXAFS analysis was limited to the first coordination shell, performing the study between 1.15 and $2.25 \AA$ in the R-space. 

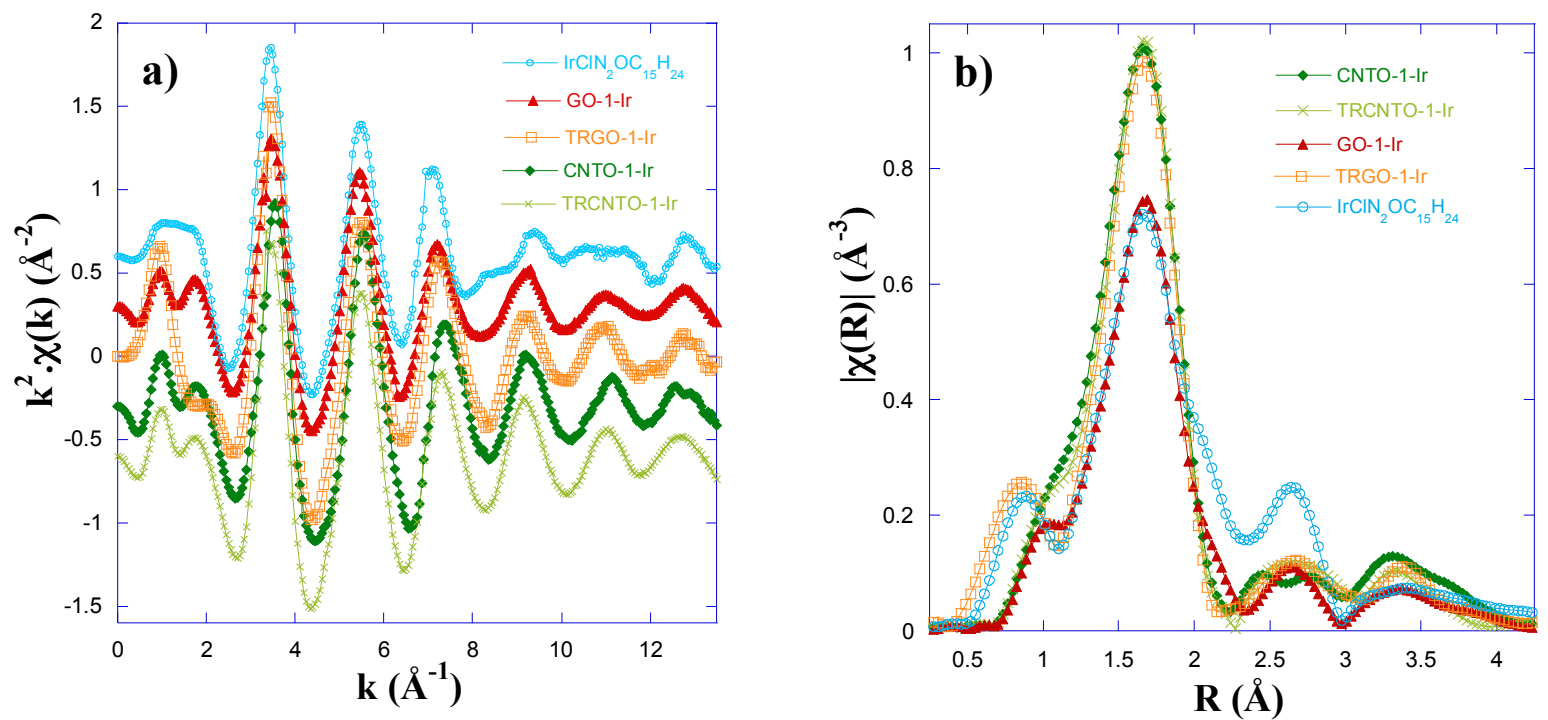

Fig. 5 - a) $\mathrm{k}^{2}$-weighted EXAFS spectra for the four hybrid catalysts and the $\left[\mathrm{IrCl}(\mathrm{cod})\left(\mathrm{MeIm}\left(\mathrm{CH}_{2}\right)_{3} \mathrm{OH}\right)\right]$ reference compound $\left(\mathrm{IrClN}_{2} \mathrm{OC}_{15} \mathrm{H}_{24}\right)$. Data are shifted in the vertical scale for the sake of comparison. b) Moduli of the FTs of the $k^{2} \chi(k)$ EXAFS signals for the same samples.

In order to obtain an accurate model for the analysis of our EXAFS data, we have drawn on our previous experience [43]. The first coordination shell of the Ir atom in the reference complex, $\left[\mathrm{IrCl}(\mathrm{cod})\left(\mathrm{MeIm}\left(\mathrm{CH}_{2}\right)_{3} \mathrm{OH}\right)\right]$, is composed of a $\mathrm{Cl}$ atom, $\mathrm{C}$ number $1\left(\mathrm{C}_{1}\right)$ in the imidazol-2-ylidene ring and $4 \mathrm{C}$ atoms of both $\mathrm{C}=\mathrm{C}$ bonds present in the cyclooctadiene ligand (see Fig. 6a). 
a)

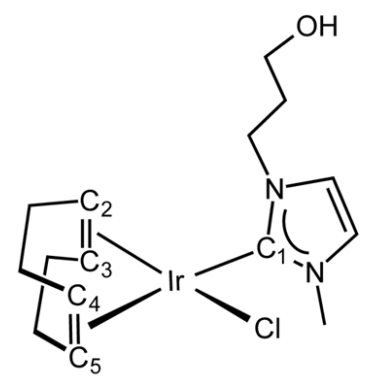

b)

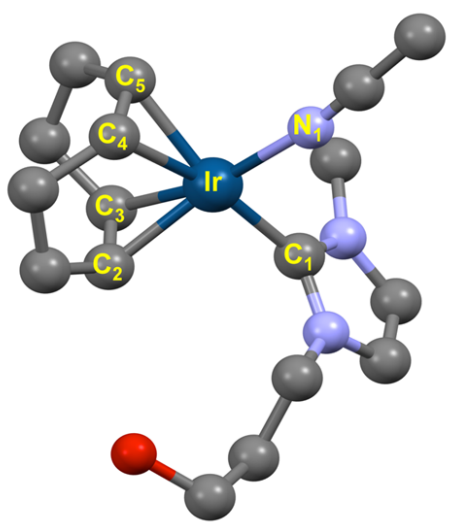

Fig. 6- a) Schematic molecular structure of the reference neutral chloride compound $\left[\mathrm{IrCl}(\mathrm{cod})\left(\mathrm{MeIm}\left(\mathrm{CH}_{2}\right)_{3} \mathrm{OH}\right)\right]$. b) Molecular structure of the cation of $\left[\operatorname{Ir}\left(\mathrm{NCCH}_{3}\right)(\mathrm{cod})\left(\mathrm{MeIm}\left(\mathrm{CH}_{2}\right)_{3} \mathrm{OH}\right)\right]\left[\mathrm{BF}_{4}\right]($ Hydrogen atoms have been omitted for clarity). Selected bond lengths $(\AA)$ and angles $\left({ }^{\circ}\right)$ : Ir-C(1) 2.031(3) , Ir-C(2) 2.127(3), Ir-C(3) 2.134(4), Ir-C(4) 2.199(3), Ir-C(5) 2.186(3), Ir-N(1) 2.032(3), C(1)-Ir-N(1) 92.44(12), C(1)-Ir-C(2) 90.58(13), $\mathrm{N}(1)-\mathrm{Ir}-\mathrm{C}(5)$ 87.55(12), C(2)-Ir-C(4) 90.11(14).

The hybrid materials should have, in principle, the $\mathrm{IrCl}(\mathrm{cod})$ metal fragment anchored to the carbon matrix (either CNTO or GO) through the NHC linker (Fig. 1). However, having in mind a possible iridium-support interaction, the ionization of the chlorido ligand cannot be discarded. Thus, replacement of the $\mathrm{Cl}$ by another anion, probably an $\mathrm{O}$ atom from the oxidized carbon matrix, could be possible. As shown in Fig. 5, the EXAFS signal rules out the presence of $\mathrm{Cl}$ atoms in the first coordination shell of these hybrid catalysts (lack of interference at $\mathrm{k} \sim 8-11 \AA^{-1}$ ), as reported in related compounds $[35,44]$. Therefore, our proposed model for the first coordination shell surrounding Ir atoms inside the catalysts is composed of five $\mathrm{Ir}-\mathrm{C}$ and one $\mathrm{Ir}-\mathrm{O}$ contributions. The Ir-C and Ir-O phase shifts and back scattering amplitudes were calculated from the square planar 
reference compound $\left[\operatorname{Ir}\left(\mathrm{NCCH}_{3}\right)(\mathrm{cod})\left(\mathrm{MeIm}\left(\mathrm{CH}_{2}\right)_{3} \mathrm{OH}\right]\left[\mathrm{BF}_{4}\right]\right.$ and their bond lengths were taken as the starting point (see Fig. 6b). The distances of Ir to the carbons in the diolefin range between $\mathrm{R}_{2}=$ $2.13 \AA$ and $\mathrm{R}_{3}=2.19 \AA$ and they are coupled in pairs $(2+2)$. The bond length to the $\mathrm{C}_{1}$ is $\mathrm{R}_{1} \sim 2.03 \AA$ and the Ir-O bond length is assumed to be close to this value. As a result, the iridium centre is bonded to six light elements with the following distribution: $R_{1}(\times 2), R_{2}(\times 2)$ and $R_{3}(\times 2)$. A total of 4 parameters are refined, with an average inner potential correction of the threshold $\left(\Delta \mathrm{E}_{0}\right)$, an average Debye-Waller factor $\left(\sigma^{2}\right)$ and two distances, $R_{2}$ and $R_{3}$ are coupled with the same free parameter. The amplitude reduction factor $\mathrm{S}_{0}{ }_{0}$ is fixed to 1 in agreement with the value obtained for the reference compounds. Fig. 7 compares the best fit and experimental spectra corresponding to the moduli of the FTs of the $\mathrm{k}^{2}$-weighted EXAFS (Fig. 7a) with the corresponding Fourier filtered spectra in k-space (Fig. 7b). There is considerable agreement in spite of the simplicity of our structural model.
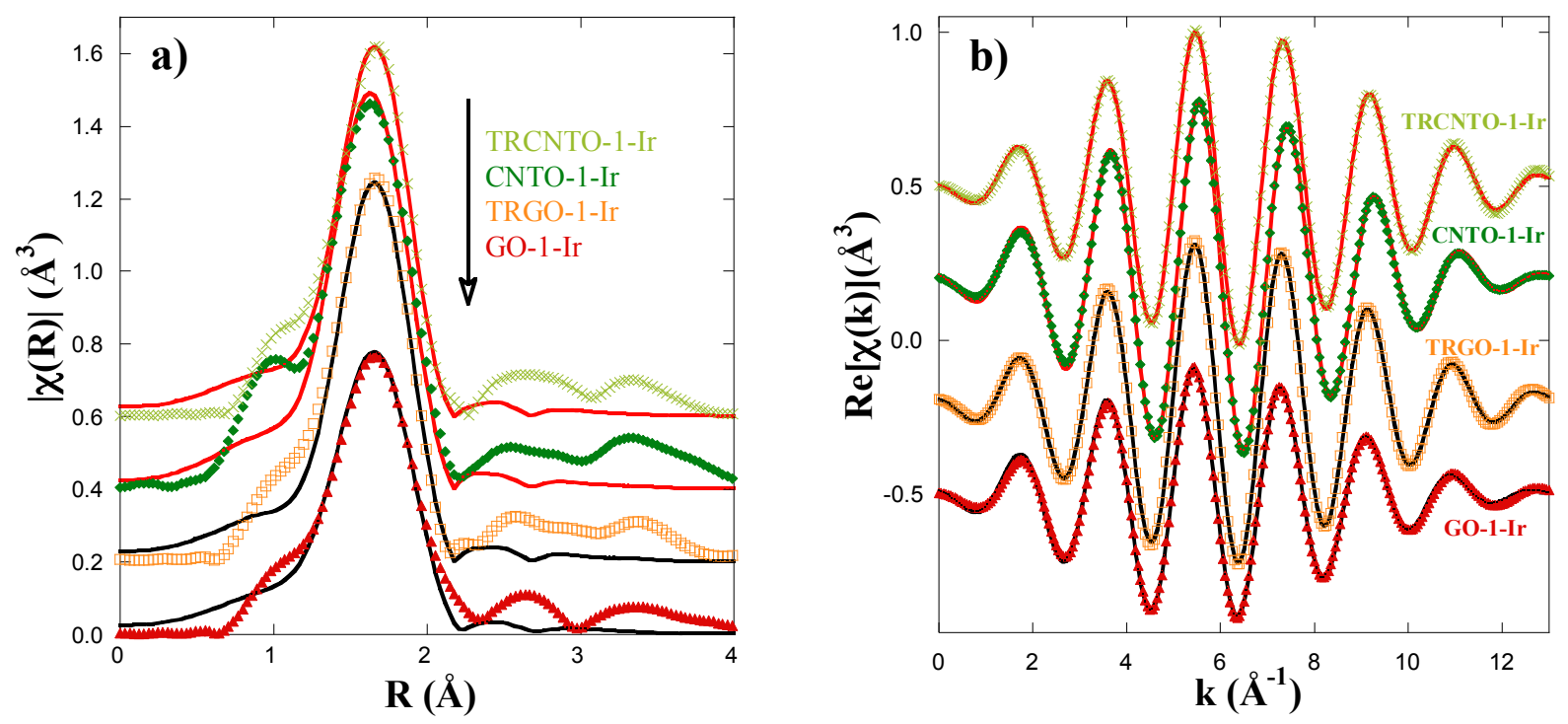

Fig. 7 - Comparison between experimental data (circles) and best fits (solid lines) for the spectra of the hybrid catalyst. a) Moduli of the FTs of the $\mathrm{k}^{2} \chi(\mathrm{k})$ EXAFS signals, and b) real part of the Fourier-filtered spectra in k-space corresponding to the first shell coordination.

The relevant structural parameters obtained for the four hybrid catalysts are summarized in Table 3. The distribution of bond lengths is very similar for the four materials and they are slightly shorter than that of the reference compound. The only significant difference concerns the GO-1-Ir 
compound that exhibits greater local disorder and this is reflected in a larger $\sigma^{2}$-value. This disorder is also reflected in the higher standard deviation of the refined distances and may indicate a broader distribution of Ir-C paths.

Table 3 - Best fit structural parameters for the first coordination shell of the hybrid catalysts at the Ir $\mathrm{L}_{3}$-edge: Average inner potential correction $(\mathrm{eV})$, bond lengths $(\AA)$, average Debye-Waller factor $\left(\AA^{2}\right)$ and a residual factor of the fit. ${ }^{\mathrm{a}}$

\begin{tabular}{lcccccc}
\multicolumn{1}{c}{ Sample } & $\boldsymbol{\Delta} \mathbf{E o}(\mathbf{e V})$ & $\mathbf{R}_{\mathbf{1}}(\AA)$ & $\mathbf{R}_{\mathbf{2}}(\AA)$ & $\mathbf{R}_{\mathbf{3}}(\AA)$ & $10^{3} \cdot \boldsymbol{\sigma}^{\mathbf{2}}\left(\AA^{\mathbf{2}}\right)$ & $\mathbf{R}_{\mathbf{F}}$ \\
\hline CNTO-1-Ir & $8.3(7)$ & $2.03(2)$ & $2.12(2)$ & $2.18(2)$ & $3.3(4)$ & 0.0029 \\
TRCNTO-1-Ir & $7.7(7)$ & $2.02(2)$ & $2.10(2)$ & $2.16(2)$ & $3.0(3)$ & 0.0028 \\
TRGO-1-Ir & $8.2(9)$ & $2.02(2)$ & $2.11(2)$ & $2.17(2)$ & $3.6(9)$ & 0.0049 \\
GO-1-Ir & $8.5(8)$ & $2.04(4)$ & $2.12(4)$ & $2.18(4)$ & $7.0(22)$ & 0.0085 \\
\hline
\end{tabular}

a The residual factor accounts for the misfit between the actual data and the theoretical calculations [51]. Numbers in parentheses are the errors estimated from different analyses to the best significant digit.

If these results are compared with the catalytic activity exhibited by these materials it will be observed that GO-1-Ir shows by far the lowest catalytic activity (Fig. 3, Table 2). This reflects the stronger local disorder of the Ir first-neighbors coordination shell in this sample that could be due to the high oxidation degree of this support (Table 1) has a negative effect on the catalytic activity of the compound. The catalytic results are however also determined by the peculiarities of the particular carbon support. It can be inferred from this results that the next-neighbors coordination shells, which are different in all the samples studied, also plays a crucial role in the catalytic system. Unfortunately, the strong disorder inferred from the EXAFS spectra prevents an accurate analysis of these coordination shells. Therefore, in order to gain more information about the "local environment" surrounding the active Ir centers in the hybrid catalyst, the XPS C1s analyses of the materials have been closely examined. The results are summarized in Fig. 8.

Similar profiles were obtained for samples TRCNTO-1-Ir and TRGO-1-Ir, which are also similar to that of CNTO-1-Ir. As the first-neighbors coordination shell of the Ir supported on these materials is similar, the differences in the catalytic activity must be related to the differences in the 
surroundings resulting from the carbon support. Interestingly, the catalytic activity of these three samples, following the order TRCNTO-1-Ir > TRGO-1-Ir > CNTO-1-Ir (Fig. 3), is enhanced with the increase in the amount of $\mathrm{Csp}^{2}$ bonds and the decrease in functional groups in the supports, which suggests that, for the catalysts with similar first-neighbors coordination shells, a more aromatic support with fewer defects would be favorable for the catalyst performance in the process under study. On the other hand, GO-1-Ir also shows the highest percentage of $\mathrm{sp}^{3}$ carbon bonds and oxygen functional groups (including the $\mathrm{C}-\mathrm{O}, \mathrm{C}=\mathrm{O}$ and $\mathrm{COO}$ groups). The poorer catalytic activity of this sample (Fig. 3) is therefore probably related to the strong local disorder in the graphene layer supporting the Ir catalyst. However, the extent of the disorder and its proximity to the Ir (particularly of the $\mathrm{C}-\mathrm{O}$ and $\mathrm{C}=\mathrm{O}$ derived functional groups in the basal planes) also seem to affect the first-neighbors coordination shell, (as can be observed from the EXAFS curves, Fig. 5 and 7) resulting in a drastic decrease in the catalytic activity.

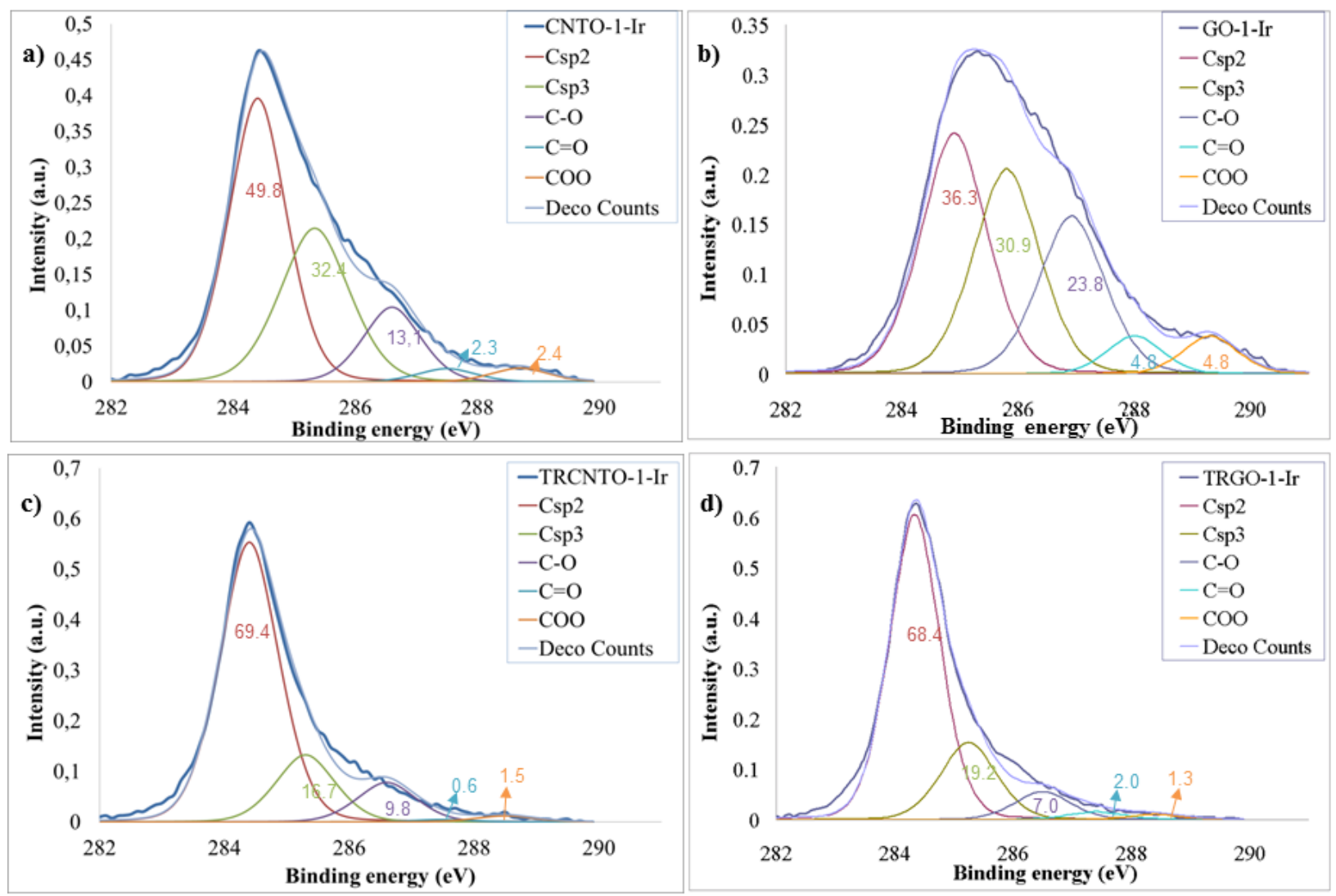


Fig. 8 - Deconvolution results of the XPS C1s curves of a) CNTO-1-Ir, b) GO-1-Ir, c) TRCNTO1-Ir and d) TRGO-1-Ir.

\section{Conclusions}

The protocol for functionalizing oxidized carbon nanomaterials through their surface $\mathrm{OH}$ groups on the basis of the activation with $p$-nitrophenylchloroformate can be successfully applied to oxidized and partially reduced carbon nanotubes in order to immobilize iridium NHC-complexes in their outer and inner walls. The carbon nanotube based iridium-NHC hybrid materials were efficient catalysts for the reduction of cyclohexanone by transfer hydrogenation. These hybrid catalysts have shown a superior catalytic performance than related graphene-based hybrid materials, prepared by the same functionalization strategy, in both the oxidized and thermally reduced graphene supports.

The study of the local structure of the iridium atoms in the hybrid catalyst by EXAFS has revealed the replacement of the chlorido ligand by an $\mathrm{O}$ atom from the oxidized carbon matrix as a result of the iridium-support interaction, which might be facilitated by the presence of a flexible linker to carbon matrix. On the other hand, as it has been shown by XPS studies, the greater number of structural defects in the graphenic based materials than in their respective nanotubes might explain their different performances. Although the same first-neighbors coordination shell is formed in every hydrid catalyst, the strong structural disorder in this very local environment leads to very poor results, as in the case of the GO-1-Ir catalyst. In contrast, the high degree of order in the $\mathrm{sp}^{2}$ lattice, combined with an appropriate amount of oxygen groups, provides a stability that enhances the catalytic activity, as in the case of TRCNTO-1-Ir.

\section{Supporting Information.}

Supplementary data associated with this article can be found, in the online version, at http://dx.doi.org/10.1016/j.carbon.Xxxxxxx.

\section{ACKNOWLEDGMENT}

The authors thank the Spanish Ministry of Economy and Competitiveness (MINECO/FEDER) (Projects Consolider Ingenio 2010 CSD2009-00050 and CTQ2013-42532-P), and the Diputación 
General de Aragón (E07 and E69) for their financial support. Dr. P. A. thanks MICINN for a Ramón y Cajal contract. J. F-T. and M. B. acknowledge their fellowships from MINECO and MECD (AP2010-0025).

\section{References}

[1] Meyer JC, Geim AK, Katsnelson MI, Novoselov KS, Booth TJ, Roth S. The structure of graphene sheets. Nature 2007;446:60-3.

[2] Novoselov KS, Geim AK, Morozov SV, Jiang D, Zhang Y, Dubonos SV et al. Electric field effect in atomically thin carbon films. Science 2004;306:666-9.

[3] Zhao J, Xie RH. Electronic and photonic properties of doped carbon nanotube. J Nanosci Nanotechno 2003;3:45978.

[4] Min SK, Kim WY, Cho Y, Kim KS. Fast DNA sequencing with a graphene-based nanochannel device. Nat Nanotechnol 2011;6:162-5.

[5] Liu Z, Bol A, Haensch W. Large-scale graphene transistors with enhanced performance and reliability based on interface engineering by phenylsilane self-assembled monolayers. Nano Lett 2011;11:523-8.

[6] Li J, Lu Y, Ye Q, Cinke M, Han J, Meyyappan M. Carbon nanotube sensors for gas and organic vapor detection. Nano Lett 2003;3:929-33.

[7] Schaetz A, Zeltner M, Stark WJ. Carbon modifications and surfaces for catalytic organic transformations. ACS Catal 2012;2:1267-84.

[8] Su C, Loh KP. Carbocatalysts: Graphene oxide and its derivatives. Acc Chem Res 2013;10:2275-85.

[9] Sarvari MH, Sharghi H. Simple and improved procedure for the regioselective acylation of aromatic ethers with carboxylic acids on the surface of graphite in the presence of methanesulfonic acid. Synthesis 2004;13:2165-68.

[10] Sarkar S, Niyogi S, Bekyarova E, Haddon RC, Organometallic chemistry of extended periodic $\pi$-electron systems: hexahapto-chromium complexes of graphene and single-walled carbon nanotubes. Chem Sci 2011;2:1326-33.

[11] Sabater S, Mata, JA, Peris E. Immobilization of Pyrene-Tagged Palladium and Ruthenium Complexes onto Reduced Graphene Oxide: An Eflicient and Highly Recyclable Catalyst for Hydrodefluorination. Organometallics, 2015;34:1186-90.

[12] Karimi S, Tavasoli A., Mortazavi Y, Karimi A. App. Cat. A-General, 2015;499:188-196.

[13] Wang D, Niu WQ, Tan MH, Wu MB, Zheng XJ, Li YP, et al. Pt Nanocatalysts Supported on Reduced Graphene Oxide for Selective Conversion of Cellulose or Cellobiose to Sorbitol. ChemSusChem, 2014;7:1398-1406.

[14] Zhu, J., Holmen A., Chen D. Carbon Nanomaterials in Catalysis: Proton Affinity, Chemical and Electronic Properties, and their Catalytic Consequences. ChemCatChem,2013;5:378-401.

[15] Castro-Neto AH, Guinea F, Peres NMR, Geim A, Novoselov K. The electronic properties of graphene. Rev Mod Phys 2009;81:109-62.

[16] White CT, Todorov TN. Carbon Nanotubes as long ballistic conductors. Nature 1998;393:240-42.

[17] Baladin AA. Thermal properties of graphene and nanostructured carbon materials. Nat Mater 2011;10:569-81. 
[18] Ovid'Ko IA. Mechanical properties of graphene. Rev Adv Mater Sci 2013;34:1-11

[19] Treacy MMJ, Ebbesen TW, Gibson JM. Exceptionally high Young's modulus observed for individual carbon nanotubes. Nature 1996;381:678-80.

[20] Zhang P, Yuan J, Li H, Liu X, Xu X, Antonietti M, et al. Mesoporous nitrogen-doped carbon for copper-mediated Ullmann C-O/-N-S cross-coupling reactions. RSC Adv, 2013;3:1890-5.

[21] Zhang P, Gong Y, Li H, Che Z, Wang Y. Solvent-free aerobic oxidation of hydrocarbons and alcohols with Pd@Ndoped carbon from glucose. Nature Commun, 2013;4:1593-5.

[22] Iijima S. Helical microtubes of graphitic carbon. Nature 1991;354:56-8.

[23] Lerf A, He H, Forster M, Klinowski JJ. Structure of graphite oxide revisited. Phys Chem B 1998;102:4477-82.

[24] Dreyer DR, Park S, Bielawski CW, Ruoff RS. The chemistry of graphene oxide. Chem Soc Rev 2010;39:228-40.

[25] Szabo T, Berkesi O, Forgo P, Josepovits K, Sanakis Y, Petridis D, et al. Evolution of surface functional groups in a series of progressively oxidized graphite oxides. Chem Mater 2006;18:2740-9.

[26] Aqel A, Abou El-Nour KMM, Ammar RAA, Al-Warthan A. Carbon nanotubes, science and technology part (I) structure, synthesis and characterization. Arab J Chem 2012;5:1-23.

[27] Sabater S, Mata JA, Peris E. Catalyst enhancement and recyclability by immobilization of metal complexes onto graphene surface by noncovalent interactions. ACS Catal 2014;4:2038-47.

[28] Georgakilas V, Otyepka M, Bourlinos AB, Chandra V, Kim N, Kemp KC et al. Functionalization of graphene: covalent and non-covalent approaches, derivatives and applications. Chem Rev 2012;112:6156-214.

[29] Li F, Zhang B, Li X, Jiang Y, Chen L, Li Y, et al. Highly Efficient oxidation of water by a molecular catalyst immobilized on carbon nanotubes. Angew Chem Int Ed 2011;50:12276-9.

[30] Tasis D, Tagmatarchis N, Bianco A, Prato M. Chemistry of carbon nanotubes. Chem Rev 2006;106:1105-36.

[31] Hamon MA, Chen J, Hu H, Chen YS, Itkis ME, Rao AM et al. Dissolution of single walled carbon nanotubes. Adv Mater 1999;11:834-40.

[32] Shen J, Shi M, Yan B, Ma H, Li N, Hu Y, et al. Covalent attaching protein to graphene oxide via diimide-activated amidation. Colloid Surf B-Biointerfaces 2010;81:434-8.

[33] Chen L, Chai S, Liu K, Ning N, Gao J, Liu Q, et al. Enhanced epoxy/silica composites mechanical properties by introducing graphene oxide to the interface. ACS Appl Mater Interfaces 2012;4:4398-404.

[34] Serp P, Corrias M, Kalck P, Carbon nanotubes and nanofibers in catalysis. Appl Cat A 2003;253:337-58.

[35] Blanco M, Álvarez P, Blanco C, Jiménez MV, Fernández-Tornos J, Pérez-Torrente JJ et al. Graphene-NHCiridium hybrid catalysts built through -OH covalent linkage. Carbon 2015;83:21-31.

[36] Modugno G, Monney A, Bonchio M, Albrecht M, Carraro M. Transfer hydrogenation catalysis by a NHeterocyclic carbene iridium complex on a polyoxometalate platform. Eur J Inorg Chem 2014;2356-60.

[37] Azua A, Mata JA, Peris E, Lamaty F, Martínez J, Colacino E. Alternative energy input for transfer hydrogenation using iridium NHC based catalysts in glycerol as hydrogen donor and solvent. Organometallics 2012;31:3911-9.

[38] Diez C, Nagel U. Chiral iridium(I) bis(NHC) complexes as catalysts for asymmetric transfer hydrogenation. App Organomet Chem 2010;24:509-16. 
[39] Hahn FE, Holtgrewe C, Pape T, Martin M, Sola E, Oro L A. Iridium complexes with N-Allyl-substituted benzimidazol-2-ylidene ligands and their application in catalytic transfer hydrogenation. Organometallics 2005;24: $2203-9$.

[40] Hillier AC, Lee HM, Stevens ED, Nolan SP. Cationic iridium complexes bearing imidazol-2-ylidene ligands as transfer hydrogenation catalysts. Organometallics 2001;20:4246-52.

[41] Gülcemal S, Gökçe A G, Çetinkaya B. N-benzyl substituted N-heterocyclic carbene complexes of iridium(I): assessment in transfer hydrogenation catalyst. Inorg Chem 2013;52: 10601-9.

[42] Türkmen H, Pape T, Hahn F E, Çetinkaya B. Efficient transfer hydrogenation using iridium and rhodium complexes of benzannulated N-Heterocyclic carbenes. Eur J Inorg Chem 2008;5418-23.

[43] Jiménez MV, Fernández-Tornos J, Pérez-Torrente JJ, Modrego FJ, Winterle S, Cunchillos C, et al. Iridium(I) complexes with hemilabile N-Heterocyclic carbenes: efficient and versatile transfer hydrogenation catalysts. Organometallics 2011;30:5493-508.

[44] Blanco M, Álvarez P, Blanco C, Jiménez MV, Fernández-Tornos J, Pérez-Torrente JJ, et al. Enhanced hydrogentransfer catalytic activity of iridium N-Heterocyclic carbenes by covalent attachment on carbon nanotubes. ACS Catal 2013;3:1307-17.

[45] Blanco M, Álvarez P, Blanco C, Campos N, Gómez D, Menéndez R. Influence of the alignment degree of CVDgrown carbon nanotubes on their functionalization and adsorption capacity. Diam Relat Mater 2013;37:1-7.

[46] Botas C, Álvarez P, Blanco C, Santamaría R, Granda M, Gutiérrez M D, et al. Critical temperatures in the synthesis of graphene-like materials by thermal exfoliation-reduction of graphite oxide. Carbon 2013;52:476-85.

[47] Bekhouche M, Blum L J, Doumèche B. Ionic liquid-inspired cations covalently bound to FDH improve its stability and activity in IL. ChemCatChem 2011;3:875-82.

[48] Usón R, Oro L A, Cabeza J A. Dinuclear Methoxy, Cyclooctadiene, and Barrelene Complexes of Rhodium(I) and Iridium(I). Inorg Synth 1985;23:126-7.

[49] Sherwood PMA. In Practical Surface Analysis in Auger and X-ray Photoelectron Spectroscopy; Briggs D, Seah M P. Eds.; Wiley: New York, 1990, Vol. 1, pp. 574.

[50] Elgrabli D, Floriani M, Abella-Gallar S, Meunier L, Gamez C, Delalain P, et al. Biodistribution and clearance of instilled carbon nanotubes in rat lung. Part Fibre Toxicol 2008;5:20-33.

[51] Ravel B, Newville M, ATHENA, ARTEMIS, HEPHAESTUS: data analysis for X-ray absorption spectroscopy using IFEFFIT. J Synchrotron Radiat 2005;12:537-41.

[52] Rehr JJ, Albers RC. Theoretical approaches to x-ray absorption fine structure. Rev Mod Phys 2000;72:621-54.

[53] Letsinger R L, Ogilvie K K. Use of p-nitrophenyl chloroformate in blocking hydroxyl groups in nucleosides. J Org Chem 1967;32:296-300.

[54] Oh JK, Drumright R, Siegwart DJ, Matyjaszewski K. The development of microgels/nanogels for drug delivery applications. Prog Polym Sci 2008;33:448-77.

[55] Chiang YC, Lin WH, Chang YC. The influence of treatment duration on multi-walled carbon nanotubes functionalized by $\mathrm{H}_{2} \mathrm{SO}_{4} / \mathrm{HNO}_{3}$ oxidation. Applied Surface Science 2011;257:2401-10.

[56] Lu J, Serna P, Aydin C, Browning ND, Gates BC. Supported molecular iridium catalysts: Resolving effects of metal nuclearity and supports as ligands. J Am Chem Soc 2011;133:16186-95. 
[57] Crotti C, Farnetti E, Filipuzzi S, Stener M, Zangrando E, Moras P. Evaluation of the donor ability of phenanthrolines in iridium complexes by means of synchrotron radiation photoemission spectroscopy and DFT calculations. Dalton Trans 2007;133-42. 